Revista Brasileira de Agricultura Irrigada v.12, nº.5, p. 2854 - 2865, 2018

ISSN 1982-7679 (On-line)

Fortaleza, CE, INOVAGRI - http://www.inovagri.org.br

DOI: $10.7127 /$ rbai.v12n500838

Protocolo 838.18 - 16/12/2017 Aprovado em 03/09/2018

\title{
CORREÇÃO DE SOLO SALINO-SÓDICO COM CONDICIONADORES E DOSES DE FÓSFORO PARA CULTIVO DO SORGO SACARINO
}

\author{
Francisco Vanies da Silva Sá ${ }^{1 *}$, Marcos Eric Barbosa Brito², Luderlândio de Andrade \\ Silva $^{3}$, Rômulo Carantino Lucena Moreira ${ }^{3}$, Emanoela Pereira de Paiva ${ }^{4}$, Lauter Silva Souto ${ }^{5}$
}

\section{RESUMO}

Objetivou-se com esse trabalho avaliar os atributos químicos do solo, a emergência e o crescimento inicial de plantas de sorgo sacarino em solo salino sódico tratado com gesso e enxofre elementar sob diferentes doses de fósforo. O experimento foi arranjado em esquema fatorial 2 x 5, em delineamento de blocos casualizados, com dois tratamentos de correção do solo salino-sódico (gesso e enxofre elementar) e 5 doses de superfosfato simples $(0,0 ; 50,0$; 100,$0 ; 150,0$ e 200,0 $\mathrm{mg} \mathrm{dm}^{-3}$ ), com 3 repetições, perfazendo 30 unidades experimentais, sendo cada parcela representada por dois vasos. Para isso, amostras de um solo salino-sódico foram submetidas à correção com gesso e enxofre elementar a $100 \%$ da necessidade de gesso, e posterior lavagem com duas vezes o volume de poros, e fertilização com diferentes doses de fósforo. Após 20 dias da adubação foram semeadas três sementes de sorgo sacarino em cada vaso. As plantas de sorgo sacarino foram conduzidas por 30 dias após a semeadura, e avaliadas quanto à emergência, crescimento e acúmulo de fitomassa, após a coleta dos dados biométricos, amostras de solo foram coletadas para caracterização química. O enxofre elementar é mais eficiente na redução da salinidade e sodicidade do solo, em relação ao gesso agrícola. A dose de $90 \mathrm{mg} \mathrm{dm}^{-3}$ de superfosfato simples proporcionou a melhor emergência, crescimento e acúmulo de fitomassa nas plantas de sorgo sacarino cultivadas nos solos corrigido com gesso e enxofre elementar.

Palavras-chave: enxofre elementar, gesso agrícola, salinidade, Sorghum bicolor, superfosfato simples.

\footnotetext{
${ }^{1}$ Eng. Agrônomo, Doutor em Engenharia Agrícola, Programa Nacional de Pós-Doutorado - CAPES, Universidade Federal Rural do Semi-Árido, Campus Mossoró, Mossoró-RN. E-mail: vanies_agronomia@hotmail.com

${ }^{2}$ Eng. Agrônomo, Doutor em Engenharia Agrícola, Professor, Universidade Federal de Sergipe, Campus do Sertão, Nossa Senhora da Glória-SE. E-mail: marcoseric@ufs.br

${ }^{3}$ Eng. Agrônomo, Doutorando em Engenharia Agrícola, Universidade Federal de Campina Grande, Campus Campina Grande, Campina Grande-PB. E-mail: luderlandioandrade@gmail.com; romulocarantino@gmail.com

${ }^{4}$ Eng. Agrônoma, Doutora em Fitotecnia, Programa Nacional de Pós-Doutorado - CAPES, Universidade Federal Rural do Semi-Árido, Campus Mossoró, Mossoró-RN. E-mail: emanuelappaiva@hotmail.com

${ }^{5}$ Eng. Agrônomo, Doutor em Agronomia, Professor, Universidade Federal de Campina Grande, Campus Pombal, Pombal-PB. E-mail: lauter@ccta.ufcg.edu.br

*Autor Correspondente.
} 


\title{
CORRECTION OF SALINE-SODIUM SOIL WITH CONDITIONERS AND DOSES OF PHOSPHORUS FOR CULTIVATION OF SACCHARIN SORGHUM
}

\begin{abstract}
The objective of this work was to evaluate soil chemical attributes, emergence and initial growth of sorghum plants in sodium saline soil treated with gypsum and elemental sulfur under different doses of phosphorus. The experiment was arranged in $2 \times 5$ factorial scheme, in a randomized complete block design, with two treatments of saline-sodium soil (gypsum and elemental sulfur) and 5 doses of simple superphosphate (0.0, 50, 0, 100.0, 150.0 and $200.0 \mathrm{mg}$ $\mathrm{dm}^{-3}$ ), with 3 replicates, making up 30 experimental units, each plot being represented by two vessels. For this, samples of a saline-sodium soil were submitted to correction with gypsum and elemental sulfur at $100 \%$ of the need for gypsum, and subsequent washing with twice the volume of pores, and fertilization with different doses of phosphorus. After 20 days of fertilization, three sorghum seeds were sown in each pot. Sorghum sorghum plants were harvested for 30 days after sowing, and evaluated for emergence, growth and phytomass accumulation, after collecting the biometric data, soil samples were collected for chemical characterization. The elemental sulfur is more efficient in the reduction of soil salinity and sodicity in relation to agricultural gypsum. The dose of $90 \mathrm{mg} \mathrm{dm}^{-3}$ of single superphosphate provided the best emergence, growth and phytomass accumulation in sorghum plants cultivated in soils corrected with gypsum and elemental sulfur.
\end{abstract}

Keywords: elemental sulfur, gypsum, salinity, Sorghum bicolor, superphosphate simple.

\section{INTRODUÇÃO}

Nos últimos anos o interesse pela cultura do sorgo sacarino [Sorghum bicolor (L.) Moench] vem aumentando, visto que a cultura apresenta-se como uma nova alternativa bioenergética devida o sua grande capacidade de geração de biomassa com elevado teor de fibras e açúcares fermentáveis, para a produção de biocombustíveis (SANTOS et al., 2014).

Desse modo a sua capacidade de gerar biomassa associado a- sua moderada tolerância a salinidade (LACERDA et al., 2005), indicam como um potencial alternativa para fitorremediação de solo salinos-sódicos, auxiliando na recuperação desses solos e incluindo-os como alternativa para expansão da área cultivada pela cultura.

A recuperação dos solos salinos, salinosódicos e sódicos tem, como principal objetivo, a diminuição das concentrações dos sais solúveis e do sódio trocável no perfil do solo, deixando-o apto para a agricultura (VASCONCELOS et al., 2013). Essa recuperação pode ser favorecida pela exportação de biomassa das culturas, haja vista, que junto a esta também são exportados sais. No entanto, o destino dessa biomassa é fator importante devido à capacidade da reincorporação dos sais pela decomposição da matéria orgânica vegetal (FREIRE; FREIRE, 2006; MIRANDA et al., 2010). Com isso, plantas como o sorgo, amplamente difundidas para alimentação animal são alternativas viáveis para difusão dessa biomassa.

No entanto, o processo de recuperação de solos afetados por sais por meio de fitorremediação é lento, sendo necessária a utilização de corretivos químicos para uma maior eficiência e rapidez no processo de recuperação desses solos (ARAÚJO et al., 2011; SOUZA et al., 2012; SÁ et al., 2013a). Os autores reportam que a utilização de corretivos como gesso e o enxofre elementar apresentam grande potencial para a correção desse solo, tanto pela eficácia quanto pela facilidade de manuseio.

Recentemente o uso de fertilizantes em consórcios com corretivos para a correção de solos afetados por sais vem sendo foco de pesquisas. Porém resultados sobre essas interações, ainda são incógnitas, 
principalmente no que diz respeito ao fósforo, tendo em vista que seus efeitos positivos nesses solos salinos ainda não são claros (VITAL et al., 2005). Menezes Junior et al. (2010) verificaram que adubação fosfata com superfosfato simples e ácido fosfórico exerceu efeitos positivos no crescimento de plantas de milhento em solo salino-sódico tratado com gesso e com ácido sulfúrico. Acredita-se que o aumento da disponibilidade desse nutriente estimule o desenvolvimento radicular, que por sua vez é restrito nesses tipos de solo (KHALIL et al., 1967).

Considerando que o aumento da salinidade dos solos está associado à redução dos potenciais osmóticos e consequentemente o potencial hídrico, fatores que limitam a germinação de sementes, estudos sobre a germinação e o desenvolvimento inicial das plântulas nessas condições são importantes (BETONI et al., 2011). Larcher (2000) afirma que a avaliação do processo de germinação e emergência pode indicar a sensibilidade das plantas à salinidade em estádios subsequentes do crescimento e do desenvolvimento.

Com isso, objetivou-se com esse trabalho avaliar os atributos químicos do solo, a emergência e o crescimento inicial de plantas de sorgo sacarino em solo salino sódico tratado com gesso e enxofre elementar sob diferentes doses de fósforo.

\section{MATERIAL E MÉTODOS}

O experimento foi conduzido no período de janeiro a junho de 2013, em casa de vegetação do Centro de Ciências e Tecnologia Agroalimentar (CCTA), da Universidade Federal de Campina Grande (UFCG), Campus de Pombal, Paraíba, utilizando-se amostras de um Neossolo Flúvico salino-sódico, não cultivado. As amostras foram obtidas aleatoriamente, na profundidade de $0-40 \mathrm{~cm}$, em lote pertencente ao Setor de Fruticultura do Instituto Federal de Educação, Ciência e Tecnologia da Paraíba (IFPB-PB), localizado no Perímetro Irrigado de São Gonçalo, a 10 km do município de Sousa.

Depois de secadas ao ar, destorroadas e passadas em peneira de malha de $2,0 \mathrm{~mm}$, as amostras de solo foram encaminhadas ao Laboratório de Solos e Nutrição de Plantas do CCTA/UFCG, onde foram classificadas quanto à salinidade, usando-se os valores de pHes, CEes (condutividade elétrica do extrato de saturação), e os teores solúveis de Ca, Mg, K e Na e PST (Percentagem de Sódio Trocável), conforme Richards (1954) (Tabela 1).

Tabela 1. Caracterização da pasta saturada da amostra de solo salino-sódico antes e após correção com gesso agrícola e enxofre elementar segundo metodologia de Richards (1954).

\begin{tabular}{cccccccc}
\hline Solo & $\mathrm{pHes}$ & $\mathrm{CEes}$ & $\mathrm{Ca}^{+2}+\mathrm{Mg}^{+2}$ & $\mathrm{Na}^{+}$ & $\mathrm{K}^{+}$ & $\mathrm{RAS}$ & $\mathrm{PST}$ \\
\hline & & $\mathrm{dS} \mathrm{m} \mathrm{m}^{-1}$ & $\ldots \ldots \ldots \ldots \ldots . . \mathrm{mmol}_{\mathrm{C}} \mathrm{L}^{-1} \ldots \ldots \ldots \ldots \ldots \ldots \ldots \ldots \ldots$ & & $\left(\mathrm{mmol}_{\mathrm{C}} \mathrm{L}^{-1}\right)^{0,5}$ & $(\%)$ \\
Inicial* & 9,40 & 39,90 & 7,00 & 289,7 & 0,30 & 489,7 & 87,8 \\
Gesso* & 8,17 & 5,32 & 19,60 & 27,3 & 0,40 & 8,71 & 10,39 \\
Enxofre* & 8,31 & 5,45 & 9,40 & 28,2 & 0,48 & 13,01 & 15,20 \\
\hline
\end{tabular}

*Amostra de solo inicial; Solo após correção com gesso ou com enxofre elementar, mais lavagem.

Com base nos resultados da análise de solo, procedeu-se com a correção do solo com aplicação de gesso agrícola ou de enxofre elementar, conforme tratamento, sendo a dose de gesso agrícola (NG) calculada com base no teor de sódio trocável do solo, visando diminuir a PST para $15 \%$. Já a quantidade de enxofre elementar (S) foi calculada usando o produto analítico (PA), cuja dose foi calculada com base na dose de gesso determinada, objetivando fornecer a mesma quantidade de enxofre fornecida por meio do gesso.

Após a aplicação dos corretivos, os solos foram mantidos por 30 dias com umidade correspondente a 70\% da capacidade de campo. A fase seguinte correspondeu à lavagem dos solos, aplicando-se um volume de água (CE < 0,3 dS.m ${ }^{-1}$ ), equivalente a duas vezes a porosidade total do solo. Após a lavagem, foram retirados cerca de $300 \mathrm{~g}$ de solo, com os 
quais foi realizada uma nova caracterização química, conforme os procedimentos anteriormente descritos (Tabela 1).

Após a nova caracterização química do solo, procedeu-se a aplicação do segundo fator, correspondente a 5 doses de superfosfato simples: $\mathrm{P}_{1}=0,0 ; \mathrm{P}_{2}=50,0 ; \mathrm{P}_{3}=100,0 ; \mathrm{P}_{4}=$ 150,0 e $\mathrm{P}_{5}=200,0 \mathrm{mg} \mathrm{dm}^{-3}$ de superfosfato simples (18 \% $\left.\mathrm{P}_{2} \mathrm{O}_{5} ; 18 \% \mathrm{Ca}^{+2} ; 10 \% \mathrm{SO}_{4}^{-}\right)$. Unindo-se os fatores, em um delineamento em blocos casualizados, obteve-se como resultado 10 tratamentos (2 Tratamentos de correção do solo (Cor) x 5 doses de superfosfato simples (P)), com 3 repetições, perfazendo 30 unidades experimentais, sendo cada parcela representada por dois recipientes.

Após a aplicação das doses de superfosfato simples, o solo foi acondicionado em vasos com capacidade para $2 \mathrm{dm}^{3}$ de volume e incubados por 20 dias com umidade próxima à capacidade máxima de retenção, antes da realização da semeadura.

As reposições de água durante a incubação e as irrigações basearam-se no método da lisimétria de drenagem, sendo a lâmina aplicada acrescida de uma fração de lixiviação de $15 \%$. O volume aplicado (Va) por recipiente foi obtido pela diferença entre a lamina anterior ( $\mathrm{La}$ ) aplicada menos a média de drenagem (d), dividido pelo número de recipientes (n), como indicado na equação 1:

$$
\mathrm{Va}=\frac{\mathrm{La}-\mathrm{D}}{\mathrm{n}(1-\mathrm{Fl})}
$$

Após a incubação, realizou-se a semeadura na razão de três sementes por recipiente, totalizando 6 sementes por parcela, realizou-se o raleio quando as plantas estavam com duas folhas definitivas, mantendo-se apenas uma planta em cada recipiente. O substrato para o desenvolvimento das plantas foi o solo corrigido acrescido das respectivas doses de superfosfato simples. Foi feita uma adubação suplementar utilizando solução modificada de Hogland e Arnom (1950) na proporção de $5 \%$ do volume do substrato aos 10 dias após semeadura quando se obteve a total emergência das plantas (Tabela 2).

Tabela 2. Concentração dos nutrientes na solução nutritiva para cultivo hidropônico proposta por Hoagland e Arnon, (1950) ajustada ao experimento.

\begin{tabular}{|c|c|c|c|c|c|c|}
\hline \multirow{2}{*}{ Nutrientes } & $\mathrm{N}$ & $\mathrm{P}$ & K & $\mathrm{Ca}$ & Mg & $\mathrm{S}$ \\
\hline & \multicolumn{6}{|c|}{$\left(\mathrm{mmol}^{-1}\right)$} \\
\hline Concentração & 15 & 0 & 6 & 5 & 2 & 2 \\
\hline \multirow{2}{*}{ Nutrientes } & $\mathrm{Fe}$ & Mn & B & $\mathrm{Cu}$ & $\mathrm{Zn}$ & Mo \\
\hline & \multicolumn{6}{|c|}{...........(mmol L $\left.{ }^{-1}\right) \ldots}$. \\
\hline Concentração & 0,0625 & 0,01 & 0,05 & 0,003 & 0,0008 & 0,001 \\
\hline
\end{tabular}

A emergência das plantas de sorgo foi monitorada por meio de contagens do número de plântulas emergidas, ou seja, com o coleóptilo acima do nível do solo, foram realizadas diariamente, sem que estas fossem descartadas, obtendo-se, portanto, um valor cumulativo. Dessa maneira, o número de plântulas emergidas referentes a cada contagem foi obtido subtraindo-se do valor lido com o valor referente à leitura do dia anterior. Dessa forma, com o número de plântulas emergidas referentes a cada leitura, obtido em casa de vegetação, foram calculados a velocidade de emergência (VE) (dias), o índice de velocidade de emergência (IVE) (dias) e o coeficiente de velocidade de emergência (CVE) (dias), empregando-se as seguintes fórmulas descrita por Schuab et al. (2006):

$$
\begin{gathered}
V E=\frac{\left(N_{1} G_{1}\right)+\left(N_{2} G_{2}\right)+\cdots+\left(N_{n} G_{n}\right)}{G_{1}+G_{2}+\cdots+G_{n}} \\
I V E=\frac{\left(N_{1}\right)+\left(N_{2}\right)+\cdots+\left(N_{n}\right)}{G_{1}+G_{2}+\cdots+G_{n}} \\
C V E=\frac{G_{1}+G_{2}+\cdots+G_{n}}{\left(N_{1} G_{1}\right)+\left(N_{2} G_{2}\right)+\cdots+\left(N_{n} G_{n}\right)} \times 100
\end{gathered}
$$

Onde: VE = velocidade de emergência (dias); IVE = índice de velocidade de emergência; $\mathrm{CVE}=$ coeficiente de velocidade de emergência; $\mathrm{G}$ e $\mathrm{N}=$ possuem o mesmo significado das fórmulas anteriores. 


\section{CULTIVO DO SORGO SACARINO}

Após a estabilização da emergência aos 10 dias após a semeadura (DAS) foi determinada a percentagem de emergência (PE) (\%), obtido pela relação entre o número de plantas emergidas e o número de sementes usadas na semeadura.

Aos 30 DAS foi avaliado a altura de planta (AP) (cm), medida com uso de uma régua graduada, pela distância entre o solo e o ápice das plantas; o diâmetro do colmo (DC) (mm), medido com uso de um paquímetro digital no colo das plantas; e o número de folhas (NF), a partir da contagem das folhas maduras. Ainda, aos 30 DAS, coletou-se as plantas para obtenção da fitomassa seca da parte aérea (FSPA) (g), fitomassa seca da raiz (FSR) (g), a partir da coleta do material, partição e acondicionamento em estufa de circulação de ar, a $65^{\circ} \mathrm{C}$, para secagem do material que, após (72 h), foi pesado em balança analítica. De posse destes dados, foi possível mensurar a relação raiz/parte aérea (RRPA), por meio do cociente entre a fitomassa seca da raiz pela fitomassa seca da parte aérea.

Ao termino do experimento os substratos foram coletados e analisados quanto à salinidade representada pelas seguintes variáveis; condutividade elétrica (CEes) $\left(\mathrm{dS} \mathrm{m}^{-}\right.$ $\left.{ }^{1}\right)$, Potencial hidrogeniônico $(\mathrm{pH})$, relação de absorção de sódio (RAS) (mmol L L $)^{-1,5}$ e

A

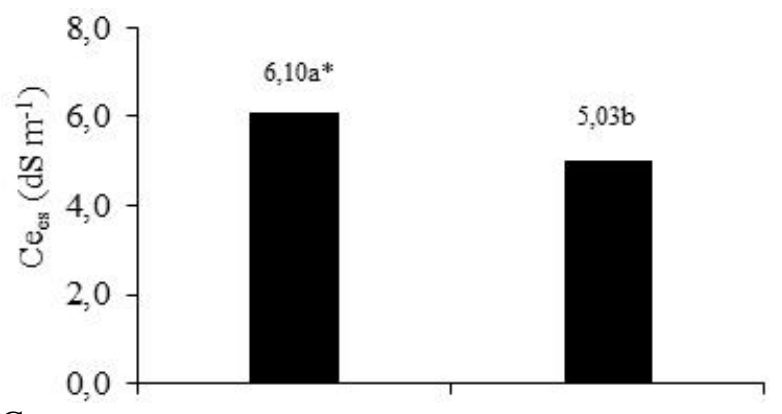

C

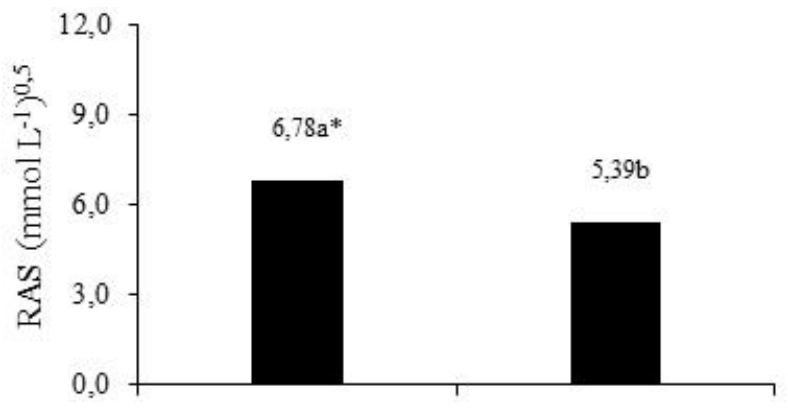

percentagem de sódio trocável (PST) (\%) da pasta de saturada segundo metodologia de Richards, (1954). Equações 5 e 6 descritas por Richards (1954).

$$
\begin{gathered}
\mathrm{RAS}=\frac{\mathrm{Na}}{\sqrt{\frac{(\mathrm{Ca}+\mathrm{Mg})}{2}}} \\
\mathrm{PST}=\frac{100 \times(0,01475 \times \mathrm{RAS}-0,0126)}{1+(0,01475 \times \mathrm{RAS}-0,0126)}
\end{gathered}
$$

Os dados obtidos foram avaliados mediante análise de variância pelo teste F. Nos casos de significância, foi realizado teste de médias (Tukey ao nível de $5 \%$ de probabilidade) para o fator 'corretivo' e análise de regressão polinomial (linear ou quadrática) para o fator 'doses de superfosfato simples' com auxilio do software SISVAR (FERREIRA, 2011).

\section{RESULTADOS E DISCURSÃO}

Houve influência significativa $(\mathrm{p}<0,05)$ dos fatores isolados, corretivos e doses de fósforo sob as variáveis condutividade elétrica, relação de adsorção de sódio e percentagem de sódio trocável (Figura 1A, B, C, D, E e F).

B

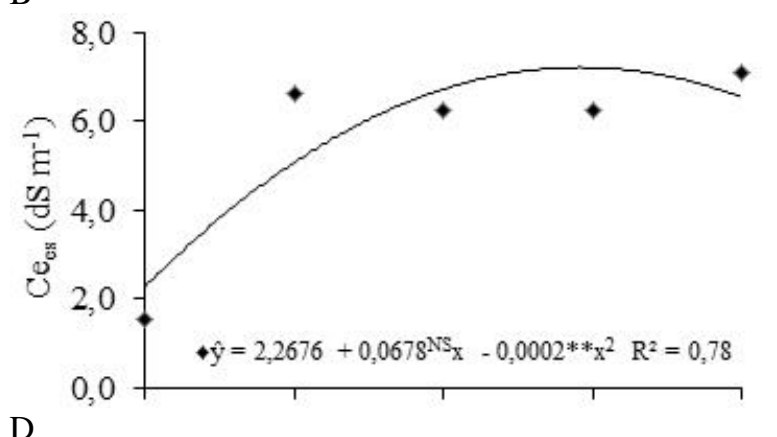

D

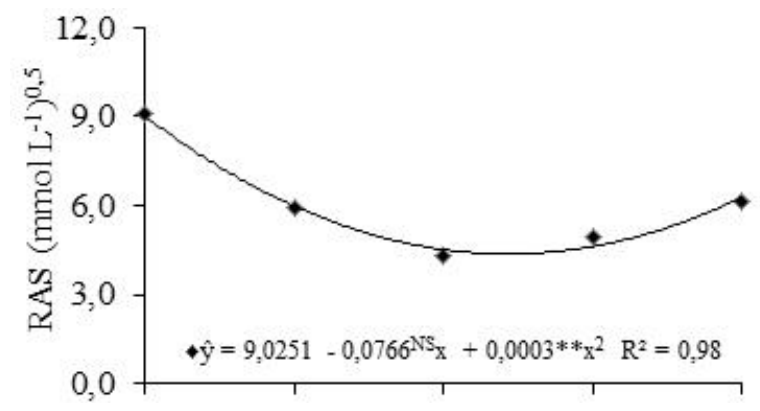


Sá et al.

E

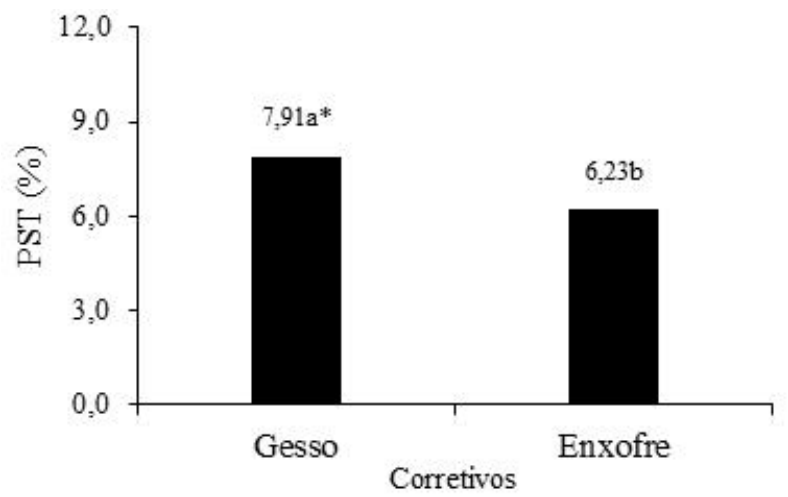

$\mathrm{F}$

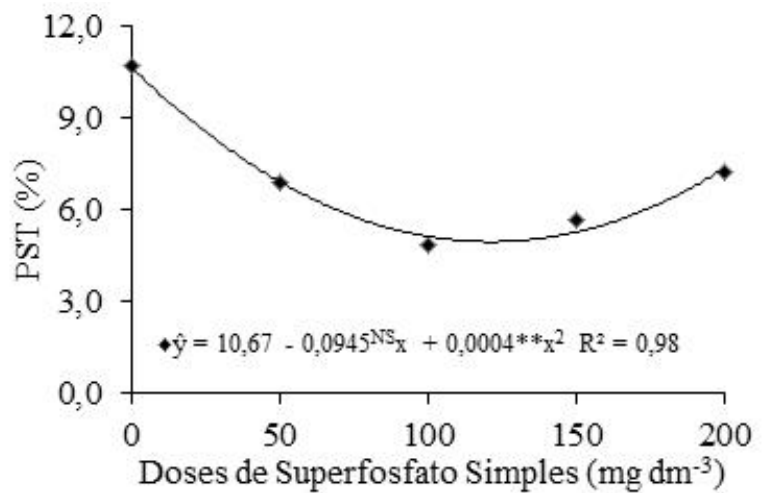

NS $\mathrm{e}^{* *}=$ Não significativo e significativo a $1 \%$ de probabilidade $(\mathrm{p}<0,01)$, respectivamente. Letras iguais não diferem perante o teste de Tukey a $5 \%$ de probabilidade.

Figura 1. Condutividade elétrica, $C E_{\text {es }}(A$ e B), relação de absorção de sódio, RAS (C e D) e percentagem de sódio trocável, PST (E e F) de um solo salino-sódico tratado com corretivos e doses de superfosfato simples.

O solo tratado com enxofre elementar sob lavagem continua, ao longo da incubação do adubo fosfatado independente da dose utilizada, promove reduções de 21,2, 25,7 e 26,9\% a mais na condutividade elétrica, RAS e PST do solo, em relação ao tratamento com gesso agrícola (Figura 1A, C e E). Esse fato é relacionado à baixa solubilidade do cálcio presente no gesso e no superfosfato simples, limitando a liberação de cálcio no solo. Além de que reação acida do enxofre elementar no solo promover uma maior decomposição de minerais (SÁ et al., 2013b), podendo reagir com superfosfato simples, aumentando a velocidade de reação do mesmo, aumento dos teores de cálcio, sulfato e fósforo no solo, que associados a lavagem aumentam a eficiência da remoção do sódio solúvel do solo, exercendo efeito direto sob a RAS e a PST do solo.

As doses de fósforo até $122 \mathrm{mg} \mathrm{dm}^{-3} \mathrm{de}$ superfosfato simples aumentaram a Cees do solo independente do corretivo utilizado, no entanto, com o aumento da Cees houve reduções na RAS e PST até a respectiva dose (Figuras $1 \mathrm{~B}, \mathrm{D}$ e F). $\mathrm{O}$ aumento da condutividade elétrica pode ser relacionado a composição do adubo fosfatado que também contém sais de sulfato de cálcio. Melo et al. (2008) e Tavares Filho et al. (2012) trabalhando com doses crescentes de gesso em solos salino-sódicos, também verificaram aumento da condutividade elétrica do solo em função dos sais sais de sulfato de cálcio. Os autores também verificaram que apesar do aumento da $\mathrm{CE}_{\text {es }}$ houve reduções nos valores de RAS e PST dos dois solos salinos estudados. Esse fenômeno pode estar relacionado à capacidade do Cálcio em deslocar os íons de sódio das micelias do solo auxiliando na remoção do mesmo pelo fenômeno da lavagem.

Houve interação significativa $(\mathrm{p}<0,05)$ entre os corretivos e as doses de SFS sobre o $\mathrm{pH}$ dos solo salino-sódico (Figura 2). Houve comportamento quadrático do $\mathrm{pH}$ dos solos tratados com gesso agrícola e enxofre elementar em função da doses de SFS, observado reduções no PH até as doses de 190 e 187 (mg $\mathrm{dm}^{-3}$ ), averiguando-se os valores de $\mathrm{pH}$ de 4,46 e 4,20, respectivamente (Figura 2). Com isso, verifica-se que aplicação com SFS associada à lavagem continua favorece a redução do $\mathrm{pH}$ do solo independente do corretivo utilizando, no entanto, $\mathrm{pH}_{\text {es }}$ é maior no solo tratado com gesso agrícola independente da dose de SFS, possivelmente devido a reação ácida do enxofre elementar no solo, onde o mesmo é convertido em ácido sulfúrico antes de reagir com os minerais do solo. Esse comportamento também foi verificado por Sousa et al. (2012) e Sá et al. (2013a) trabalhando com distintos corretivos para a recuperação de solos salino-sódicos. 


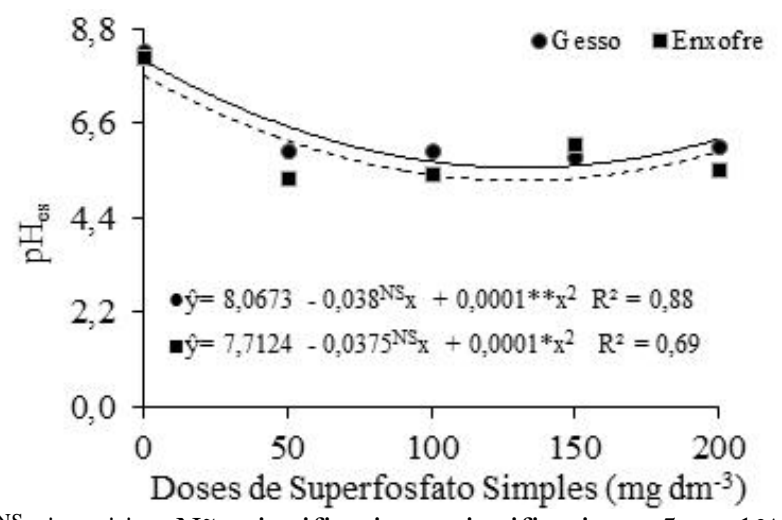

NS, *, e ** = Não significativo e significativo a 5 e a $1 \%$ de probabilidade $(\mathrm{p}<0,05$ e $\mathrm{p}<0,01)$, respectivamente.

Figura 2. Potencial hidrogeniônico, $\mathrm{pH}$, de um solo salino-sódico tratado com corretivos e doses de superfosfato simples.

Houve interação significativa $(\mathrm{p}<0,05)$ das doses de superfosfato simples e dos

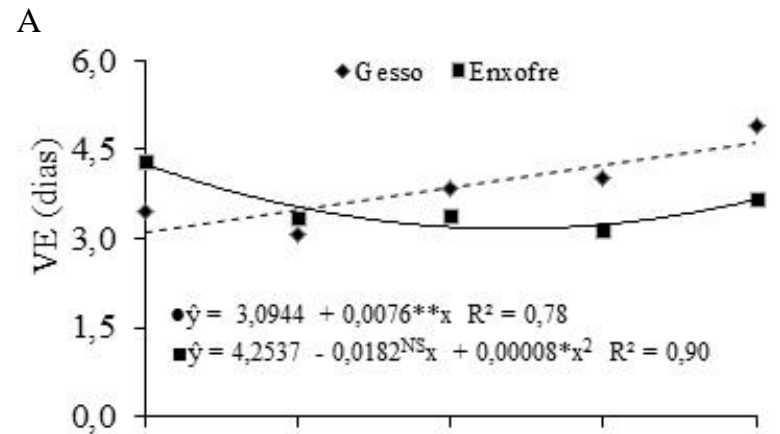

C

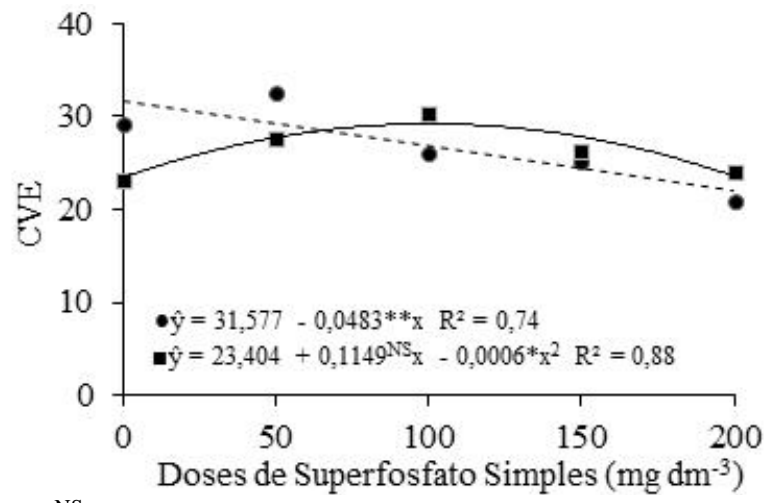

corretivos sob a emergência das sementes de sorgo. Observou-se resposta linear crescente para velocidade de emergências nos solos tratados com gesso agrícola em função do aumento das doses de superfosfato simples, averiguando-se aumento unitário de (0,0076 dias) para emergência das plântulas (Figura 3A). Verifica-se também, comportamento linear decrescente para índice de velocidade de emergência, coeficiente de velocidade de emergência e percentagem de emergência com reduções (0,0062 dias), (0,0483 dias) e $(0,1889 \%)$ respectivamente, para cada aumento unitário da dose de superfosfato simples nos solos tratados com gesso agrícola (Figura 3B, C e D).

B

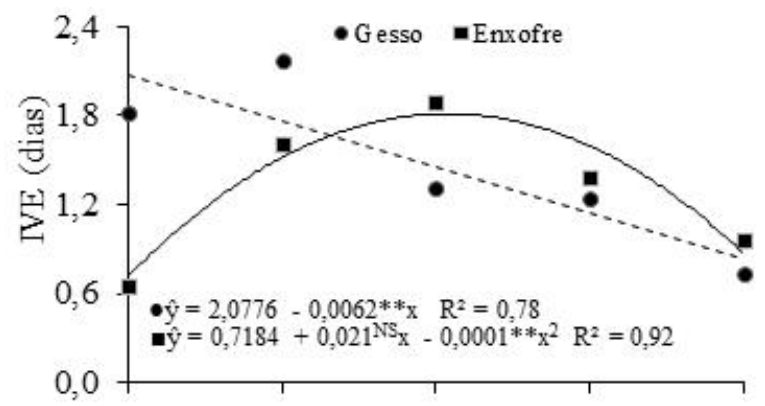

D

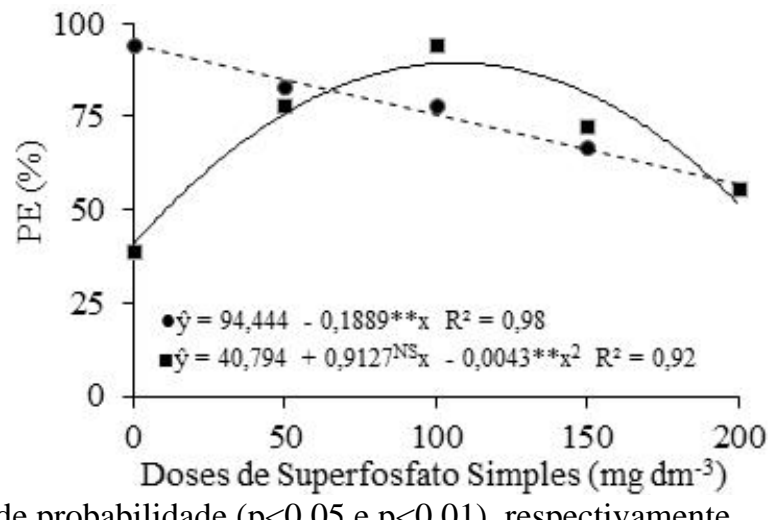

Figura 3. Velocidade de emergência, VE (A), o índice de velocidade de emergência, IVE (B), coeficiente de velocidade de emergência, CVE (C) e percentagem de emergência, PE (D) de plântulas de sorgo sacarino em solo salino-sódico tratado com corretivos e doses de superfosfato simples.

As restrições no processo de emergência da cultura, possivelmente em função do aumento da salinidade do solo, haja vista que além de fósforo o fertilizante é fonte de cálcio $(18 \%)$ e sulfato (10\%), elevando a condutividade elétrica do solo (Figura 1 A e B), reduzindo o potencial osmótico do solo a níveis que impossibilitassem a embebição das sementes, principalmente quando associado as baixos níveis de $\mathrm{pHes}$ observados no solo após o tratamento com SFS (Figura 2). Todavia, os resultados de percentagem de emergência 
obtidos pelas doses de $100\left(\mathrm{mg} \mathrm{dm}^{-3}\right)$ de $75,6 \%$ estão dentro da faixa ótima observada por Silva et al. (2011), avaliando o teor de água na colheita e temperatura de secagem na qualidade de sementes de sorgo, durante o armazenamento.

No solo tratado com enxofre, observou-se resposta quadrática das variáveis de emergência, sendo verificado que as dose de superfosfato simples de 113,7; 105,0; 95,7 e $106,1 \mathrm{mg} \mathrm{dm}^{-3}$, proporcionaram as melhores velocidade de emergência (3,21 dias), índice de velocidade de emergência (1,82 dias), coeficiente de velocidade de emergência $(28,90$ dias) e percentagem de emergência $(89,22 \%)$ (Figura 3A, B, C e D). Indicando efeitos positivos do uso do superfosfato simples associado ao corretivo ácido para a correção do solo salino-sódico. No entanto, nas maiores doses de SFS foi verificada drásticas reduções

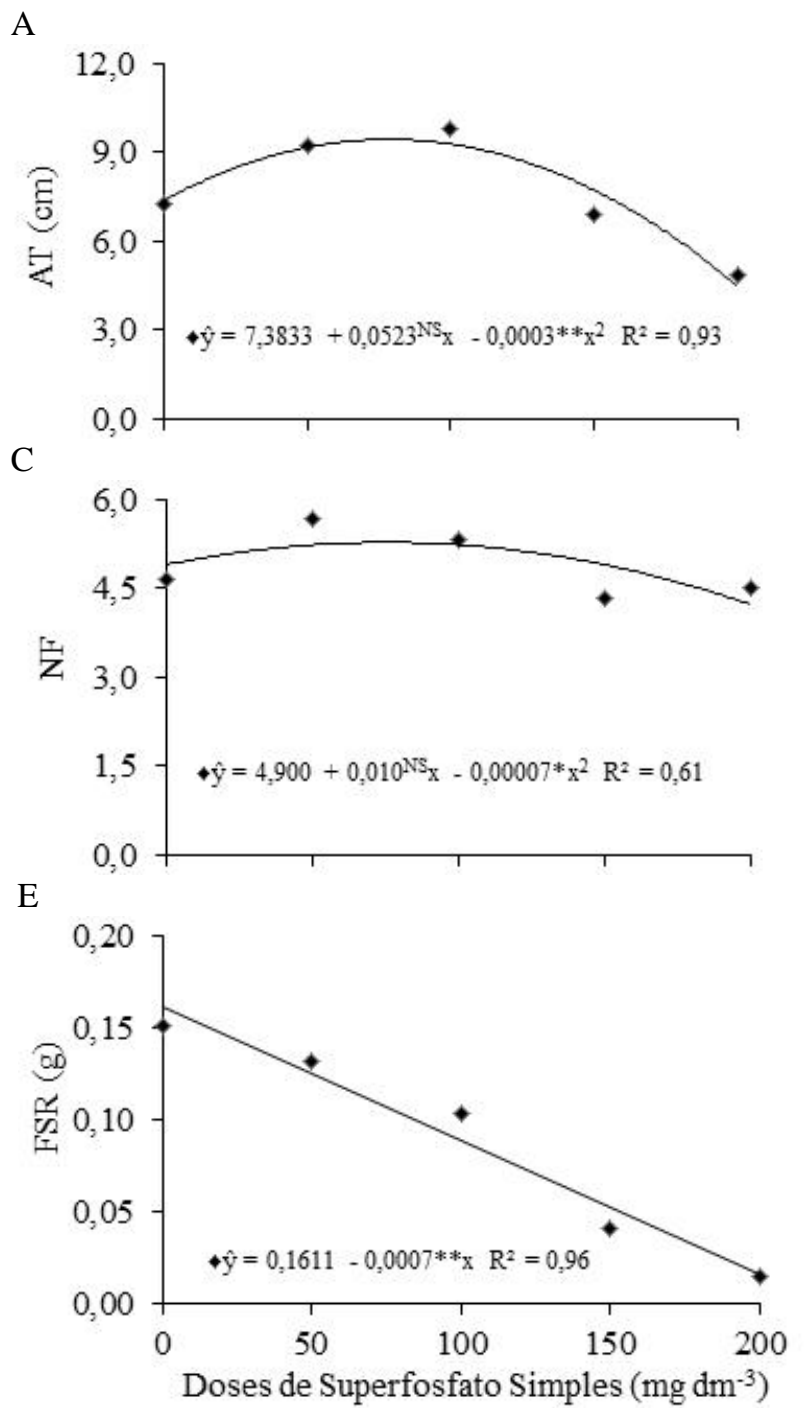

na emergência das sementes de sorgo sacarino, possivelmente em função dos baixos valores de pH observados. A acidez do solo acelerou o processo de degradação do tegumento da semente, com isso, intensificando a níveis deletérios de oxidação do embrião, afetando a germinação das sementes, visto que Neves et al. (2010) relatam que a oxidação tem relação direta com a germinação das sementes.

As doses de superfosfato simples influenciaram positivamente o crescimento inicial das plantas de sorgo sacarino independente do corretivo utilizado. Observouse ajuste quadrático das doses de superfosfato simples obtendo o melhor resultado quando aplicadas as doses de 87,1; 96,8; 71,4 e 77,5 (mg $\left.\mathrm{dm}^{-3}\right)$ para a variável altura $(9,66 \mathrm{~cm})$, diâmetro do colmo (2,68 mm) e número de folhas $(5,25$ folhas) respectivamente (Figura $4 \mathrm{~A}, \mathrm{~B}$ e $\mathrm{C})$.

B

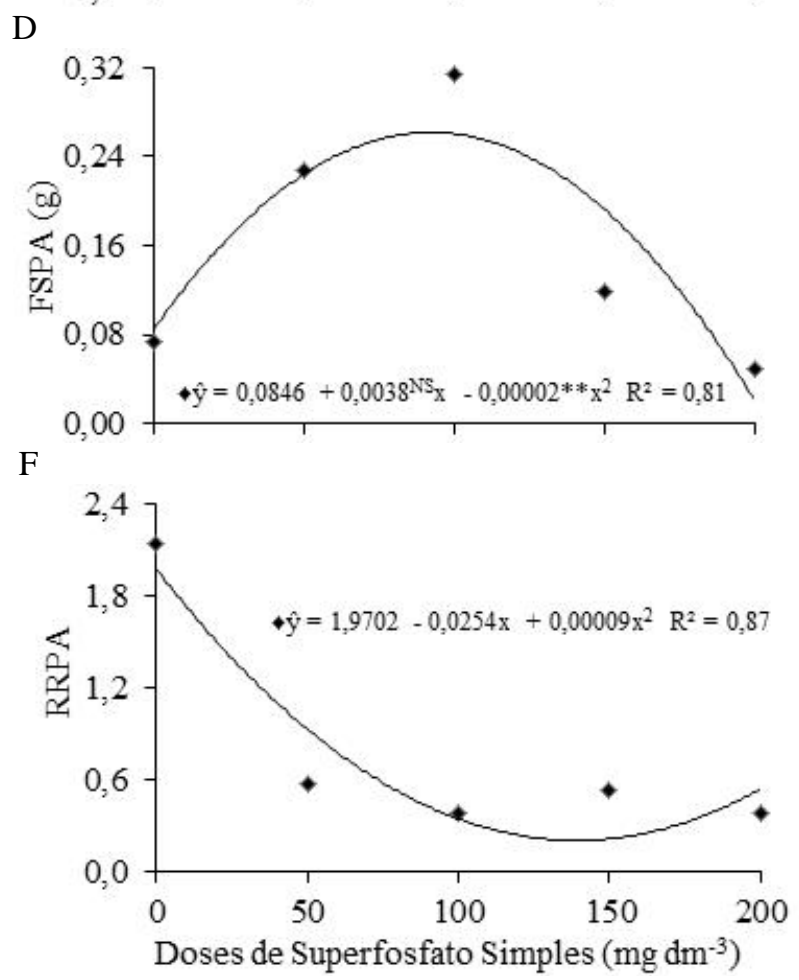


Figura 4. Altura de planta, AP (A), diâmetro do colmo, DC (B), o número de folhas, NF (C), fitomassa seca da parte aérea, FSPA (D), fitomassa seca da raiz, FSR (E) e relação raiz/parte aérea, RRPA (F) de plantas de sorgo sacarino 30 DAS em solo salino-sódico tratado com corretivos e doses de superfosfato simples.

Verifica-se ainda que doses superiores a $100\left(\mathrm{mg} \mathrm{dm}^{-3}\right)$ promoveram drásticas reduções no crescimento das plantas de sorgo, o que pode estar atrelado as grande redução do $\mathrm{pH}$ do solo com as maiores doses de SFS (Figura 2), exercendo efeito toxico por excesso de hidrogênio sob as plantas, afetando o crescimento das plantas (Figura 4A, B e C).

Os resultados benéficos da adubação adequada com SFS podem estar relacionados à composição química dos superfosfato simples que além de ser uma fonte comercial de fósforo indispensável para o crescimento e divisão celular, além de ser componente básico da adenosina trifosfato (ATP) moeda energética vital para o desenvolvimento vegetal (TAIZ; ZEIGER, 2013). Servindo ainda, como fonte de nutrientes como o e enxofre e cálcio devido a sua composição química que e acrescida de sulfato de cálcio (18\% Ca e 10\% S), componente básico do gesso agrícola, capaz de transloucar o sódio presente nas micelas do solo e facilitar na remoção do solo no perfil do solo pelo processo de lavagem (SÁ et al., 2013a). Desse modo, a redução do sódio associado o aumento dos teores de cálcio e fósforo no solo favorece ao maior crescimento das plantas.

Respostas positivas da adubação fosfatada sob o crescimento de plantas de do sorgo em condições de salinidade foi verificada por Larcerda et al. (2006) trabalhando em sistema hidropônico continuo. Sá et al. (2018), constataram que o aumento da salinidade da água afeta o crescimento e o acúmulo de matéria seca das plantas de sorgo sacarino, porém a adubação com superfosfato simples reduz a salinidade e sodicidade do solo, amenizando o efeito do estresse salino sobre as plantas de sorgo sacarino. Menezes Junior et al. (2010) verificaram que adubação fosfata com SFS e ácido fosfórico exerceu efeitos positivos no crescimento de plantas de milhento em solo salino-sódico tratado com gesso e com ácido sulfúrico. Tais resultados, indicam que a utilização do superfosfato simples em concentrações adequadas associado a corretivos químicos e lavagem, é promissora na recuperação de solos salino-sódicos.

Observou-se resposta significativa $(\mathrm{p}<$ 0,05 ) do acúmulo de fitomassa das plantas de sorgo sacarino as doses de superfosfato simples. Observou-se ajuste quadrático no acúmulo de fitomassa seca da parte aérea, com pico máximo de produção de fitomassa sob a dose de $95 \mathrm{mg} \mathrm{dm}^{-3}$ de superfosfato simples, obtendo-se 0,26 g (Figura 4D). A fitomassa seca da raiz foi reduzida linearmente em função do aumento da dose de superfosfato simples, com redução unitária de $0,007 \mathrm{~g}$ (Figura 4E), possivelmente a menor expansão do sistema radicular esteja relacionada a reduções verificadas no $\mathrm{pH}_{\mathrm{es}}$, em função das altas doses de SFS associadas a lixiviação continua do solo.

O aumento da produção de biomassa na parte aérea é relacionada à redução dos feitos deletérios da toxicidade de íons específicos (sódio) sob as plantas (FLOWERS; FLOWERS, 2005), em função da sua lixiviação, e redução da competição do sódio com outros nutrientes no processo de absorção radicular. Além do aumento da disponibilidade de fósforo, favorecendo a absorção, minimizando o gasto de energia da planta. Segundo Epistien e Bloom (2006) o estresse nutricional proporcionado pela salinidade é um dos principais agravantes do crescimento vegetal.

Estudando a relação raiz parte aérea das plantas de sorgo, observou-se redução do acúmulo de fitomassa das raízes em relação à fitomassa da parte aérea, em função da adubação com superfosfato simples até a dose $141 \mathrm{mg} \mathrm{dm}^{-3}$ (Figura 4F). Após essa dose verifica-se uma estabilização do acúmulo de fitomassa das plantas. A redução da RRPA indica o maior investimento de fotoassimlado para o crescimento da parte aérea, paravelmente devido a maior disponibilidade de fósforo no solo.

\section{CONCLUSÕES}


O enxofre elementar é mais eficiente na redução da salinidade e sodicidade do solo, em relação ao gesso agrícola.

A dose de $90 \mathrm{mg} \mathrm{dm}^{-3}$ de superfosfato simples proporcionou a melhor emergência, crescimento e acúmulo de fitomassa nas plantas de sorgo sacarino cultivadas nos solos corrigido com gesso e enxofre elementar.

\section{REFERÊNCIAS}

ARAÚJO, A. P. B.; COSTA, R. N. T.; LACERDA, C. F. DE; GHEYI, H. R. Análise econômica do processo de recuperação de um solo sódico no Perímetro Irrigado de CuruPentecoste, CE. Revista Brasileira de Engenharia Agrícola e Ambiental, v. 15, n. 4, p. 377-382, 2011. http://dx.doi.org/10.1590/S141543662011000400008.

BETONI, R.; SCALON, S. P. Q.; MUSSURY, R. M. Salinidade e temperatura na germinação e vigor de sementes de mutambo (Guazuma ulmifolia LAM.) (Sterculaceae). Revista Árvore, v. 35, n. 3, p. 605-616, 2011. http://dx.doi.org/10.1590/S010067622011000400004.

EPSTEIN, E.; BLOOM, A. J. Nutrição mineral de plantas: Princípios e perspectivas. 2.ed. Londrina: Planta, 2006. 403p.

FERREIRA, D. F. Sisvar: a computer statistical analysis system. Ciência e Agrotecnologia, v. 35, n. 6, p. 1039-1042, 2011. http://dx.doi.org/10.1590/S141370542011000600001.

FLOWERS, T. J.; FLOWERS, S. A. Why does salinity pose such a difficult problem for plant breeders? Agricultural Water Management, v. 78, n. 1, p. 15-24, 2005. https://doi.org/10.1016/j.agwat.2005.04.015

FREIRE, M. B. S.; FREIRE, F. J. Fertilidade do solo e seu manejo em solos afetados por sais. In: NOVAIS, R. F.; ALVAREZ V.; V. H.;
BARROS, N. F.; FONTES, R. L. F.; CANTURUTTI, B.; NEVES, J. C. L. Fertilidade do solo. Viçosa: SBCS, 2006, p. 929-954.

HOAGLAND, D. R.; ARNON, D. I. The water-culture method for growing plants without soil. Berkeley, California Agricultural Experiment Station, 1950. 32p. (Circular, 347)

KHALIL, M. A.; AMAR, F.; ELGABALY, M. M. A salinity-fertility study on corn and cotton. Soil Science Society of America Proceedings, v. 31, n. 4, p. 683-686, 1967. https://doi.org/10.2136/sssaj1967.0361599500 3100050021x.

LACERDA, C. F.; CAMBRAIA, J.; OLIVA, M. A.; RUIZ, H. A. Changes in growth and in solute concentration in sorghum leaves and roots during salt stress recovery. Environmental and Experimental Botany, v. 54, n. 1, p. 69-76, 2005. https://doi.org/10.1016/j.envexpbot.2004.06.00 4.

LARCHER, W. Ecofisiologia vegetal. São Carlos: Rima, 2000. 529p.

MELO, R. M.; BARROS, M. F. C.; SANTOS, P. M.; ROLIM, M. M. Correção de solos salinosódicos pela aplicação de gesso mineral. Revista Brasileira de Engenharia Agrícola e Ambiental, v. 12, n. 4, p. 376-380, 2008. http://dx.doi.org/10.1590/S141543662008000400007.

MENEZES JÚNIOR, J. C.; SANTOS, R. V.; SOBRINHO, W. N., SOUTO, J. S. Emprego de acondicionadores químicos, fontes e doses de fósforo em solo degradado por sais na produção do milheto (Pennisetum glaucum L.). Revista Acadêmica Ciências Agrárias e Ambientais, v. 8, n. 1, p. 39-45, 2010. http://dx.doi.org/10.7213/cienciaanimal.v8i1.1 0409.

MIRANDA, M. A.; OLIVEIRA, E. E. M.; SANTOS, K. C. F.; FREIRE, M. B. G. S.; ALMEIDA, B. G. Condicionadores químicos e 
orgânicos na recuperação de solo salino-sódico em casa de vegetação. Revista Brasileira de Engenharia Agrícola e Ambiental, v. 15, n. 5, p. 484-490, 2011.

http://dx.doi.org/10.1590/S141543662011000500008.

NEVES, S. C.; RIBEIRO, L. M.; SILVA, P. O.; ANDRADE, I. G. Germinação in vitro de embriões de coquinho-azedo [Butia capitata (Mart.) Becc. (Arecaceae)] obtidos de frutos com diferentes graus de maturação. Revista de Biologia Neotropical, v. 7, n. 1, p. 47-54, 2010. https://doi.org/10.5216/rbn.v7i1.13855.

RICHARDS, L. A. Diagnosis and improvement of saline and alkali soils. Washington: US Department of Agriculture, 1954. 160p. USDA AgriculturalHandbook, 60.

SÁ, F. V. S.; ARAÚJO, J. L.; NOVAIS, M. C.; SILVA, A. P.;PEREIRA, F. H. F.;LOPES, K. P. Crescimento inicial de arbóreas nativas em solo salino-sódico do nordeste brasileiro tratado com corretivos. Revista Ceres, v. 60, n. 3, p. 388-396, 2013a. http://dx.doi.org/10.1590/S0034737X2013000300012.

SÁ, F. V. S.; ARAUJO, J. L.; NOVAES, M. C.; OLIVEIRA, S. R. Crescimento inicial de craibeira em solo salinizado corrigido com enxofre elementar. Irriga, v. 18, n. 4, p. 647660 , 2013b. http://dx.doi.org/10.15809/irriga.2013v18n4p6 47.

SÁ, F. V. S.; MESQUITA, E. F.; MELO, U. A.; PAIVA, E. P.; BERTINO, A. M. P.; MOREIRA, R. C. L. Crescimento e biomassa em plantas de sorgo sacarino irrigados com água salina sob adubação fosfatada. Revista Brasileira de Agricultura Irrigada, v. 12, n. 2, p. 2561-2569, 2018. http://dx.doi.org/10.7127/rbai.v12n200826.

SANTOS, F. C. S.; ALBUQUERQUE FILHO, M. R.; RESENDE, A. V.; OLIVEIRA, A. C.; GOMES, T. C.; OLIVEIRA, M. S. Adubações nitrogenada e potássica no sorgo biomassa - produtividade e qualidade de fibra. Revista Brasileira de Milho e Sorgo, v. 13, n. 1, p. 113, 2014. http://dx.doi.org/10.18512/19806477/rbms.v13n1p1-13.

SCHUAB, S. R. P.; BRACCINI, A. L.; FRANÇA NETO, J. B.; SCAPIM, C. A.; MESCHEDE, D. K. Potencial fisiológico de sementes de soja e sua relação com a emergência das plântulas em campo. Acta Scientiarum Agronomy, v. 28, n. 4, p. 553561 , 2006. http://dx.doi.org/10.4025/actasciagron.v28i4.9 28.

SILVA, T. T. A.; OLIVEIRA, J. A.; CARVALHO, M. L. M.; VIEIRA, A. R.; RICARDO RESENDE COSTA, R. R.; ABREU, L. A. S. Teor de água na colheita e temperatura de secagem na qualidade de sementes de sorgo, durante o armazenamento. Revista Brasileira de Milho e Sorgo, v. 10, n. 1, p. 66-81, 2011. http://dx.doi.org/10.18512/19806477/rbms.v10n1p66-81.

SOUSA, F. Q; ARAÚJO, J. L.; SILVA, A. P.; PEREIRA, F. H. F.; SANTOS, R. V.; LIMA, G. S. Crescimento e respostas fisiológicas de espécies arbóreas em solo salinizado tratado com corretivos. Revista Brasileira de Engenharia Agrícola e Ambiental, v. 16, n. 2, p. 173-181, 2012. http://dx.doi.org/10.1590/S141543662012000200007.

TAIZ, L.; ZEIGER, E. Fisiologia vegetal. 4. ed. Porto Alegre: Artmed, 2013. 853p.

TAVARES FILHO, A. N.; BARROS, M. F. C.; ROLIM, M. M.; SILVA, E. F. F. Incorporação de gesso para correção da salinidade e sodicidade de solos salino-sódicos. Revista Brasileira de Engenharia Agrícola e Ambiental, v. 16, n. 3, p. 247-252, 2012. http://dx.doi.org/10.1590/S141543662012000300002.

VASCONCELOS, R. R. A.; BARROS, M. F. C.; SILVA, E. F. F.; GRACIANO, E. S. A.; 
FONTENELE, A. J. P. B.; SILVA, N. M. L. Características físicas de solos salino-sódicos do semiárido pernambucano em função de diferentes níveis de gesso. Revista Brasileira de Engenharia Agrícola e Ambiental, v. 17, n. 12, p. 1318-1325, 2013. http://dx.doi.org/10.1590/S141543662013001200010.
VITAL, A. F. M.; SANTOS, R. V.; CAVALCANTE, L. F.; SOUTO. J. S. Comportamento de atributos químicos de um solo salino-sódico tratado com gesso e fósforo. Revista Brasileira de Engenharia Agrícola e Ambiental, v. 9, n. 1, p. 30-36, 2005. http://dx.doi.org/10.1590/S141543662005000100005. 